\title{
TOWARDS TUNGSTEN PLASMA-FACING COMPONENTS IN KSTAR: RESEARCH ON PLASMA-METAL WALL INTERACTION
}

S.-H. Hong ${ }^{a, b, c, *}$, K. -M. Kimª ${ }^{a}$ J. -H. Song ${ }^{a}$, E.-N. Bang ${ }^{a}$, H. -T. Kim ${ }^{a}$, K. -S. Lee ${ }^{a}$, A. Litnovsky ${ }^{d}$, M. Hellwig ${ }^{d}$, D. C. Seo ${ }^{a}$, H. H. Lee ${ }^{a}$, C. S. Kang ${ }^{a}$, H. -Y. Lee ${ }^{a}$, J. -H. Hong ${ }^{e}$, J. G. Bak ${ }^{a}$, H. -S. Kim ${ }^{a}$, J.-W. Juhn ${ }^{a}$, S. -H. Son ${ }^{a}$, H.-K. Kimª ${ }^{a}$ D. Douai ${ }^{\mathrm{f}}$, C. Grisolia ${ }^{\mathrm{f}}$, J. Wu ${ }^{g}$, G.-N. Luo ${ }^{g}$, W.-H. Choe ${ }^{e}$, M. Komm ${ }^{h}$ M. van den Berg', G. de Temmerman', R. Pitts ${ }^{\mathrm{j}}$

${ }^{a}$ National Fusion Research Institute, 169-148 Gwahangno, Yusung-Gu, Daejeon, 305-333, Korea.

${ }^{b}$ Department of electrical engineering, HanYang University, Seoul, 133-791, Korea

${ }^{c}$ Department of Nuclear Fusion and Plasma Science, Korea University of Science and Technology, Daejeon, 305-333, Korea

${ }^{d}$ Forschungszentrum Jülich GmbH, Institut für Energie- und Klimaforschung - Plasmaphysik, Partner of the Trilateral Euregio Cluster (TEC), 52425 Jülich, Germany

${ }^{e}$ Department of Physics, Korea Advanced Institute of Science and Technology, Daejeon 305-701, Korea

${ }^{f}$ CEA, IRFM, Association Euratom-CEA, 13108 St Paul lez Durance, France

Institute of Plasma Physics, Chinese Academy of Sciences, Hefei, 230031, China.

${ }^{h}$ Institute of Plasma Physics AS CR, v.v.i., Za Slovankou 3, 18200 Prague 8, Czech Republic

${ }^{i}$ Dutch Institute for Fundamental Energy Research (DIFFER), Association EURATOM-FOM, Trilateral Euregio Cluster, Postbus 1207, 3430BE, Nieuwegein, The Netherlands

${ }^{j}$ ITER Organization, Route de vinon sur verdon, 13115 Saint Paul lez Durance, France

*Corresponding Author: Suk-Ho Hong

Address: National Fusion Research Institute, 169-148 Gwahangno, Yusung-Gu, Daejeon, 305-333, Korea.

Email: sukhhong@nfri.re.kr

Telephone: +82-42-879-5126, Fax: +82-42-879-5119

OS2014 abstract log number: OS3-04.

Total number of pages: 20

Total number of tables: 0

Total number of figures: 6 


\title{
TOWARDS TUNGSTEN PLASMA-FACING COMPONENTS IN KSTAR: RESEARCH ON PLASMA-METAL WALL INTERACTION
}

\author{
S.-H. Hong ${ }^{a, b, c, *}$, K. -M. Kimª ${ }^{a}$ J. -H. Song ${ }^{a}$, E.-N. Bang ${ }^{a}$, H. -T. Kim ${ }^{a}$, K. -S. Lee ${ }^{a}$, A. Litnovsky ${ }^{d}$, M. Hellwig ${ }^{d}$, D. C. Seo ${ }^{a}$, \\ H. H. Lee ${ }^{a}$, C. S. Kang ${ }^{a}$, H. -Y. Lee ${ }^{a}$, J. -H. Hong ${ }^{e}$, J. G. Bak ${ }^{a}$, H. -S. Kim ${ }^{a}$, J.-W. Juhn ${ }^{a}$, S. -H. Son ${ }^{a}$, H.-K. Kimª ${ }^{a}$ D. Douai ${ }^{\mathrm{f}}$, \\ C. Grisoliaf, J. Wu ${ }^{g}$, G.-N. Luo ${ }^{g}$, W.-H. Choe ${ }^{e}$, M. Komm ${ }^{h}$, M. van den Berg' ${ }^{i}$ G. de Temmerman', R. Pitts
}

One of main mission of KSTAR is to develop long pulse operation capability relevant to the production of fusion energy. After ITER has decided to begin with full metal wall configuration, KSTAR has planned a major upgrade to tungsten first wall similar to JET ITER-Like Wall (coatings and bulk tungsten plasma-facing components). To accomplish the upgrade, tungsten bonding technology has been developed and tested. Since leading edges of each castellation structure have to be protected, shaping of tungsten blocks has been studied by ANSYS simulation and the miniaturized castellation has been exposed to Ohmic plasma to confirm the simulation results. It is found that shaped castellation block has more heat handling capability than that of conventional block. For more dedicated experiments, a multi-purpose castellation block is fabricated and exposed to Ohmic, L- and H-mode plasmas and observed by IR camera from the top. During the fabrication and assembly of the blocks, leading edges caused by "naturally misaligned" blocks due to engineering limit with a maximum level up to $0.5 \mathrm{~mm}$ have been observed, which has to be minimized for future fusion machine. 


\section{INTRODUCTION}

In-vessel components are exposed to hash environments, namely to high heat, energy, and particle flux, and radiation. The components inside the vacuum vessel on which those particle, heat flux and radiation reach, are called plasma facing components (PFCs), and the interaction between plasma and surrounding PFC surface is called plasma-surface interaction (PSI). The consequence of PSI leads to the erosion of PFC materials and it is one of the main topics to be tackled and solved as soon as possible for future fusion reactors. Recently, ITER IO has finally decided to have full tungsten divertor from the beginning of the ITER first campaign ${ }^{1}$. Therefore, ITER will have a full metal wall configuration consisting of Beryllium and Tungsten. ASDEX Upgrade (AUG) has employed full tungsten first walls and JET has equipped beryllium and tungsten walls for ITER-relevant experiments (ITER-Like Wall) ${ }^{2,3,4,5}$. Tore Supra and EAST have started to change of major machine configuration into a tungsten divertor machine ${ }^{6,7}$.

Although we have witnessed the success of the ILW experiment at $\mathrm{JET}^{8}$, there are many open issues concerning the use of metal PFCs. KSTAR (Korean Superconducting Tokamak Advanced Research) has started research activities on tungsten PFC material since 2012 to join the global research activity of metal wall experiments ${ }^{9}$. Parallel to the research activities, KSTAR has a master plan to upgrade the entire wall into tungsten similar to that of JET ILW, namely, tungsten coated graphite at the inner wall limiter and bulk tungsten blocks at the diveror ${ }^{10}$. In this paper, we introduce the research activities towards development of tungsten wall in KSTAR.

\section{A SHORT INTRODUCTION ON KSTAR TOKAMAK AND LONG PULSE H-MODE PLASMAS}

KSTAR is a superconducting tokamak with first wall fully covered by $~ 3400$ graphite tiles on passive stabilizer made of Copper. The area of the inner wall is $54 \mathrm{~m}^{2}$ while the total volume of the vacuum vessel including all side and vertical ports is $\sim 110 \mathrm{~m}^{3}$. The minor and major radius are $\mathrm{a}=0.5 \mathrm{~m}$ and $\mathrm{R}=1.8 \mathrm{~m}$, and the corresponding plasma volume is in a range of 7$16 \mathrm{~m}^{3}$ depending on the plasma scenarios. The toroidal magnetic field $\left(\mathrm{B}_{\mathrm{T}}\right)$ is varied from 1.6 to $3.5 \mathrm{~T}$, maximum plasma current $\left(\mathrm{I}_{\mathrm{p}}\right)$ achieved is $\sim 1.0$ MA with average line density up to $\mathrm{n}_{\mathrm{e}} \sim 5 \times 10^{19} \mathrm{~m}^{-3}$.

$500 \mathrm{~kW}$ ICRH at the frequency of $30 \mathrm{MHz}\left(\right.$ at $\mathrm{B}_{\mathrm{T}}=2 \mathrm{~T}$ ) is applied, and the injected power of NBI is up to $5.0 \mathrm{MW}$, with the beam energy 70-90 keV. Two ECRH of 84 and $110 \mathrm{GHz}$ gyrotrons have capability to inject $500 \mathrm{~kW}$ for plasma heating and ECH assisted startup.

KSTAR has achieved the first H-mode shot in 2010 just after the very first boronizaion. Since then, most of KSTAR discharges are neutral beam injection (NBI) driven H-mode discharges. Typical pulse length is $~ 20$ sec, and the longest $\mathrm{H}-$ 
mode plasma shot has been achieved in 2014 with total pulse length of 49 sec with H-mode flat-top length of 43 sec. Therefore, KSTAR is ideal place to test materials for future fusion machines by utilizing long pulse ELMy H-mode discharges.

\section{DEVELOPMENT OF TUNGSTEN BONDING TECHNOLOGY}

First of all, a proper tungsten bonding technology has to be developed for the upgrade of inner wall of KSTAR. Furthermore, final goal of this research is to gain expertise on tungsten bonding technique, which can be applied to manufacture tungsten PFCs for future fusion devices like K-DEMO. Fig. 1a) shows the $10 \mathrm{~mm}$ tungsten brazed sample on 15 mm CuCrZr base with $2 \mathrm{~mm}$ pure oxygen-free high thermal conductivity (OFHC) copper interlayer. Corresponding brazing process is given in Fig. 1b). Each process is undertaken as follows: (1) Heat up to $750{ }^{\circ} \mathrm{C}$ for 30 min. of baking, further increase to $980{ }^{\circ} \mathrm{C}$, (2) Brazing at $980^{\circ} \mathrm{C}$ for $30 \mathrm{~min}$, (3) Quenching from $980{ }^{\circ} \mathrm{C}$ to $400{ }^{\circ} \mathrm{C}$ with a decreasing rate of $-90{ }^{\circ} \mathrm{C}$ /min in Ar gas, (4) Aging treatment at $470{ }^{\circ} \mathrm{C}$ for $180 \mathrm{~min}$, (5) Cool down.

A series of samples were fabricated by varying pressure load $\left(\mathrm{g} / \mathrm{cm}^{2}\right)$ to find optimum value, and the shear strength test has been performed at two different joints: one at the interface between tungsten and copper, and the other between copper and CuCrZr base. Fig. 2a) shows the two locations of joint for the shear strength test and pictures of samples after the test. Samples brazed by a pressure level of $50 \mathrm{~g} / \mathrm{cm}^{2}$ show lowest strength and separation has occurred at the interface between copper and CuCrZr in both cases. From the pressure level of $100 \mathrm{~g} / \mathrm{cm}^{2}$, the bonding at both interfaces shows better adhesion. However, rupture has always occurred at the tungsten part near the interface between tungsten and copper above the pressure level of $100 \mathrm{~g} / \mathrm{cm}^{2}$ indicating that tungsten material itself used in this experiment couldn’t sustain the shear stress: Bonding between tungsten and pure copper is strong enough to sustain the shear stress, but it is not in the case of tungsten just above the interface. Fig. 2b) shows the summary of the shear strength test and we have determined the optimum loading pressure as $200 \mathrm{~g} / \mathrm{cm}^{2}$.

\section{TEST OF TUNGSTEN MATERIALS WITH CASTELLATION BLOCKS}

Particles from the plasma follow preferentially the magnetic field lines to limiter and divertor. Materials for such high flux region have to tolerate a fluence of up to $20 \mathrm{MW} / \mathrm{m}^{2}$ during steady state operation, while materials for relatively low flux region such as main chamber wall, have a little more margin. As a consequence, two different schemes can be applied: Bulk material for limiter and divertor, and coated material for main chamber wall. 
In order to test materials, experiments will be divided into two categories: long term test and short term test. The long term test is a test for a whole campaign which is equivalent to several thousand seconds of plasma exposure time. The short term test is a test for a day or a week which is equivalent to several hundred seconds of plasma exposure time, to check the time evolution of the sample materials. Furthermore, the shape of PFCs have to be optimized to sustain high heat load by changing angle of incident of ions towards surface which reduces significant amount of peak heat load on PFCs. As a result, a new shape of castellation block is proposed ${ }^{11}$. This new shape provide much low peak heat load during the steady state operation of ITER with $10 \mathrm{MW} / \mathrm{m}^{2}$ and $20 \mathrm{MW} / \mathrm{m}^{2}$ even in the misaligned case $(0.3 \mathrm{~mm})$. A test mockup has been manufactured as a miniaturized version of ITER monoblock, which consists of two conventional and two shaped blocks aligned by 2 by 2, and each block has a dimension of $10 \mathrm{~mm} \times 10 \mathrm{~mm} \times 15 \mathrm{~mm}$ with a gap distance of $1 \mathrm{~mm}$. Several machines are participating on the development and test of new castellation design, and the results from KSTAR confirms partly the modelling results ${ }^{9}$. Nevertheless, the surface temperature of the test block couldn't be measured directly by IR camera. In order to confirm the findings provided by modelling works, the test mockup is exposed to Ohmic plasmas and the temperature evolution of both conventional and shaped blocks is measured by thermocouples installed at the bottom of each block as shown in Fig. 3. The Ohmic plasmas have been performed with a $\mathrm{B}_{\mathrm{T}}=2 \mathrm{~T}$ and a plasma current of $\mathrm{I}_{\mathrm{P}}=400 \mathrm{kA}$. Line integrated density was around $10^{19} / \mathrm{m}^{3}$. The duration of the shots was $\sim 3 \mathrm{sec}$. Fig. 3c) shows the temperature evolution of blocks exposed to one of the Ohmic shots. The blocks have direct contact with the plasma. The temperature of the conventional castellation block increases rapidly up to $180{ }^{\circ} \mathrm{C}$ in $14 \mathrm{sec}$, while that of optimized one shows much slower increase up to $120^{\circ} \mathrm{C}$ in $78 \mathrm{sec}$. When the conventional one reaches the maximum temperature of $180{ }^{\circ} \mathrm{C}$, the temperature of the optimized one is only about $80{ }^{\circ} \mathrm{C}$. This indicates clearly that the optimized one has better power handling capability compared with conventional one as expected from the ANSYS simulation ${ }^{11}$. Care must be taken, since the thermocouples were installed at the bottom of both targets. Therefore, the temperatures shown in Fig. 3c) are not surface temperature, but bulk temperature of the targets, and they don’t represent the quantified heat flux on the targets or the way how thermal energy was transferred through the target body. Furthermore, the heat flux was transiently applied, not in a steady state: Since the exposure time to plasma (direct contact) was short ( 1 sec), sharp increase of the temperature of the unshaped target in Fig. 3c) was caused by leading edge directly exposed to the plasma. Slow increase of the temperature indicated the heat flux was distributed more homogeneously on the shaped target, thus maximum temperature is much lower than that of conventional target with leading edge exposed at the given time. However, both temperature profiles approach to their thermal equilibrium 
at a temperature around $115-120^{\circ} \mathrm{C}$, indicating that they were exposed to the same level of thermal energy (both targets have almost same volume except for the shaped part less than $1 \mathrm{~mm}$ ).

For further optimization of the shape, especially for KSTAR upgrade, we have developed three different shapes of castellation blocks as shown in Fig. 4. The base design is a slight modification of the conventional castellation block of right angled square structure with $30 \mathrm{~mm} \times 20 \mathrm{~mm} \times 12 \mathrm{~mm}$ size, which is very similar with ITER mono-block. The castellation block consists of three different materials: $5 \mathrm{~mm}$ tungsten top layer, $13 \mathrm{~mm}$ CuCrZr base, and $2 \mathrm{~mm}$ pure cupper intermediate layer. One side edge of the tungsten layer has slightly different height of $4 \mathrm{~mm}$ to have a chamfer structure (see Fig. 4a). Incident angle of particles and heat flux on divertor at KSTAR is depending on the position in a range between 5 to $8{ }^{\circ}$, and we have chosen $5^{\circ}\left(3^{\circ}\right.$ in ITER) in this study. The second design is double chamfered one as shown in Fig. 4b). The slope of base design along the incident angle was cut so that some portions of surface are protected. The third is rounded edge, similar with the one proposed by A. Litnovsky et al. ${ }^{11}$ which was also tested in $\mathrm{KSTAR}^{9}$, but with different angle and radius: Edges were rounded to have the corner curvature of $3.4 \mathrm{~mm}$ radius and $1.7 \mathrm{~mm}$, respectively, as depicted in Fig. 4c). The thermal response of the blocks is simulated by ANSYS with $20 \mathrm{MW} / \mathrm{m}^{2}$ steady state perpendicular heat load with cooling $\left(150{ }^{\circ} \mathrm{C}\right)$. Note that, $20 \mathrm{MW} / \mathrm{m}^{2}$ heat load is not realistic in KSTAR, since it was adopted from the ITER scenario, but for comparison with ITER case. Nonetheless, KSTAR has already equipped active cooling system, and mono-block type tungsten PFCs shown in Fig. 4 are currently under development. One of optimized block designs in Fig. 4 would be employed for major upgrade of PFCs. The ANSYS analysis results in Fig. 4 shows that the maximum temperature of base design reaches up to $2976{ }^{\circ} \mathrm{C}$ at the leading edge, while that of the double chamfered one increases up to $2552{ }^{\circ} \mathrm{C}$. The rounded one shows the maximum temperature of $2366^{\circ} \mathrm{C}$, which is much less than that of other two designs indicating that the rounded design has more heat handling capability. The castellation blocks are manufactured and installed in KSTAR for 2014 campaign, as shown in Fig. 5a) and 5b). We have varied the base design parameters such as tungsten thickness, width, and gap distance to see any effect such as the bonding strength, transient heat transfer characteristics, and to find optimum condition. The tile is observed by divertor IR system during plasma shots to measure the temperature increase (Fig. 5c).

Fig. 5c) shows an example of divertor IR measurement of the inter-ELM heat flux during an H-mode shot. Divertor IR shows that the heat flux pattern on carbon tiles shows shadow region, where some portion of surface are hidden from the particle and heat flux. The strike point on tungsten castellation tile is also observed with a bright spot at leading edges. Since the emissivity of tungsten is different from that of carbon and we expect some carbon deposition on the surface, the thermal emission from tungsten blocks might not represents the surface temperature. Assuming toroidal symmetry, we obtain heat 
flux on carbon tile at the same poloidal location as tungsten blocks as shown in Fig. 5c). In this case, the heat flux on the surface is $3 \mathrm{MW} / \mathrm{m}^{2}$. Further analysis is under way to quantify heat flux on the inner and outer divertor.

We would like to point out an important experience during this tungsten block experiment. Although we have given enormous efforts, there was certain engineering limit on the fabrication and assembly of the tungsten block tile: the vertical alignment of each block was not perfect and there is always so called "naturally misaligned", which makes unwanted leading edges. We have measured the level of this misalignment of entire block tile by using 3D laser profiling technique. The level of the misalignment has been identified by comparing 3D height profile measurements with 3D cad drawing (perfectly aligned case) of the entire block tile. Fig. 6 shows the color map of the level of misalignment and a picture of tungsten block tile after the campaign. The green part, e.g., outer graphite shield, represents $\Delta \mathrm{h} \approx 0$. Each block has a level of misalignment of $\Delta \mathrm{h} \pm 0.25 \mathrm{~mm}$, which indicates a maximum level of misalignment of $\Delta \mathrm{h} \approx 0.5 \mathrm{~mm}$, which is larger than that allowed in ITER (0.3 mm). The consequence of the misalignment is exposure of leading edges, and shadow for particles and heat flux which can be seen in Fig. 6. The lesson from this experiment suggests that this natural misalignment has to be carefully monitored during the fabrication, assembly, and installation of ITER divertor. The tungsten blocks are disassembled for further analysis. The results will be published in forthcoming paper.

\section{SUMMARY AND DISCUSSION ON FURTHER EXPERIMENTS}

The research interests on PSI moves from low Z PFC materials to metal PFCs, and it is expected that the use of metal PFCs would be advantageous to operate a fusion power plant. KSTAR has joined the research activity on metal wall environment recently. As a first step, we have developed tungsten bonding technology and shape design optimization of the block has been performed. As a result, brazing bonding technique has been successfully developed. From the direct exposure of the castellation structures to Ohmic plasmas, it is found that shaped castellation has more heat handing capability than that of conventional design. Further optimization of the shape of the castellation blocks, three different shapes were designed, analyzed by ANSYS, and tested under H-mode discharges with deposited heat flux of 1-3 MW/ $\mathrm{m}^{2}$. Analysis is still under way. One of most important findings in this study is the naturally misaligned blocks of a maximum level of 0.5 mm caused by engineering limit, which leads to unwanted leading edges. Such misalignment should be carefully monitored.

Eroded tungsten atoms from tungsten PFCs lead to a negative effect on the plasma operation: Tungsten is a high Z material which causes radiation loss of core plasma energy. As AUG has reported, the use of metal PFCs has reduced the

operation window for the plasma experiments ${ }^{12}$. This reveals that the change of wall materials, i.e. the wall condition has 
direct influence on the plasma start up and plasma operation at flat top. Therefore, the quantification of the tungsten impurity concentration during accumulation has to be measured and removal technique of impurity from the core by ECRH or ICRH injection should be developed in parallel with the metal PFC developments. In order to investigate the tungsten concentration

during accumulation and the removal from the core, a particle injection system consisting of an injection gun, a trigger, a piezoelectric motor, and a particle storage compartment is developed ${ }^{13}$. The injection system was successfully tested under vacuum and strong magnetic field of a level of up to 7 T. A multi-machine cross comparison experiment is planned in 2015 ASDEX Upgrade, EAST, and KSTAR campaign. Once a quantitative tungsten concentration during accumulation is obtained, removal of tungsten impurities from core by ECRH or ICRH injection will be performed with theoretical modeling by using UTC-SANCO code.

Another important topic to be studied is long term fuel retention inside the gap between castellation blocks. We have analyzed the deposition inside the gaps of castellation proposed by A. Litnovsky et al. ${ }^{11}$ and found that the deposition is reduced at least by a factor of two by using optimized castellation structure ${ }^{9}$. For the removal of the deposition inside the gap during intermission, Ion Cyclotron Wall Conditioning (ICWC) has been suggested which is included into the ITER baseline for in-between plasma shots wall conditioning. Dedicated ICWC experiments in KSTAR have found that the deposition inside the gap can be treated and eroded by He ICWC plasmas ${ }^{9}$. However, the results show a strong effect at the midplane region while a weak effect at divertor region due to strong inhomogeneity of ICWC plasma. Applying vertical magnetic field could bring more homogeneous ICWC plasmas ${ }^{14}$, but still it has to be studied to enhance removal rate and efficiency.

\section{ACKNOWLEDGMENTS}

This research was partially supported by Ministry of Science, ICT, and Future Planning under KSTAR project, was partly supported by Korea Research Council of Fundamental Science and Technology (KRCF) under the international collaboration \& research in Asian countries, No PG1314), and was partially supported by National R\&D Program through the National Research Foundation of Korea (NRF) funded by the Ministry of Science, ICT, of Republic of Korea (NRF2014M1A7A1A03045092).

\section{REFERENCES}

1. ITER newsline, http://www.iter.org/newsline/274/1639

2. G. F. Matthews et al., Phys. Scr. T128 (2007) 137 
3. O. Gruber et al., Nucl. Fusion 49 (2009) 115014

4. R. Neu et al., PPCF 12B (2007) B59-B70

5. R. Dux et al., JNM 390-391 (2009) 858-863

6. J. Bucalossi et al., “The WEST project: Testing ITER divertor high heatflux component technology in a steady state tokamak environment”, Fus. Eng. Des. 89 (2014) 907-912

7. D. Yao et al., “Tungsten-copper divertor development for EAST”, 25th Symposium on Fusion Engineering, 10-14 June, 2013, San Francisco, California, USA

8. F. Romanelli et al., “Overview of the JET results with the ITER-like wall”, Nucl. Fusion 53 (2013) 104002

9. S. -H. Hong et al., "Preliminary test results on tungsten tile with castellation structures in KSTAR", Fus. Des. Eng. 89, 1704 (2014)

10. J.-G. Kwak et al., “Overview of the experiments n KSTAR”, FEC 2012, 8-13 October 2012, San Diego, California, USA

11. A. Litnovsky et al., “Optimization of ITER W-Castellation”, ITPA Div/SOL Meeting in Juelich, Jan., 2012

12. R. Neu et al., “Overview on plasma operation with a full tungsten wall in ASDEX Upgrade” J. Nucl. Mater. 438 (2013) S34-S41

13. H.Y. Lee et al., Rev. Sci. Instrum. 85 (2014) $11 \mathrm{D} 862$

14. D. Douai et al, “Overview of the International Research on Ion Cyclotron Wall Conditioning”, FEC 2012, 8-13 October 2012, San Diego, California, USA 


\section{FIGURE CAPTIONS}

Fig. 1. a) Tungsten brazed sample, b) temperature waveform for brazing process.

Fig. 2. Shear strength test of tungsten brazed sample. a) test points and pictures of samples after the test, b) Measured shear strength as a function of pressure load $\left(\mathrm{g} / \mathrm{cm}^{2}\right)$ during the brazing process (red: W-OFHC joint, black: OFHC-CuCrZr joint).

Fig. 3. Castellation samples exposed to an Ohmic discharge in KSTAR. a) Visible CCD image of the exposure, b) exposed castellation with unshaped and shaped blocks, c) the temperature evolution of each block measured by thermocouples.

Fig. 4. Three different shapes of castellation structures for further optimization of the shape together with ANSYS simulation results. a) base design, b) double chamfered design, c) rounded design

Fig. 5. a) Manufactured castellation blocks with different design parameters such as tungsten thickness, block width, and gap distance, b) block installed in KSTAR, c) IR observation during an H-mode plasma shot from the top.

Fig. 6. The color map of the level of misalignment and a picture of tungsten block tile after the campaign. 
a)

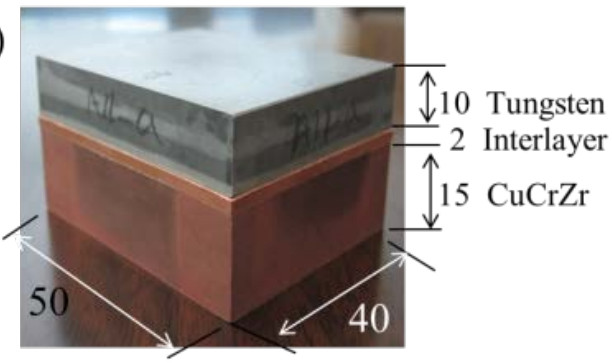

Tungsten brazed sample

\section{$\operatorname{Temp}\left({ }^{\circ} \mathrm{C}\right)$}

b) 1000

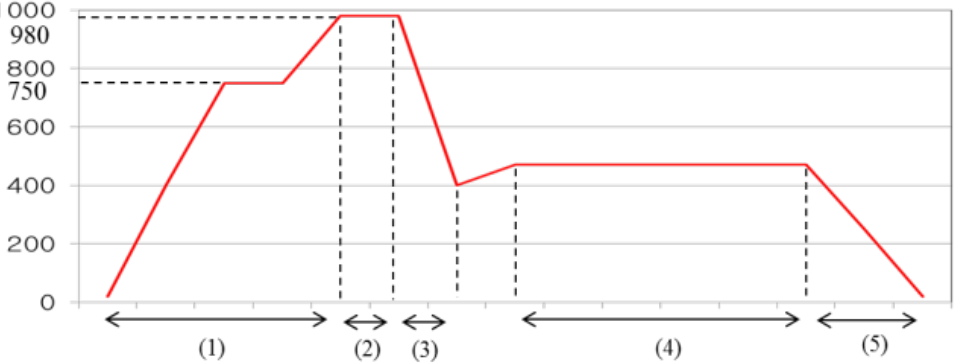

Fig. 1. a) Tungsten brazed sample, b) temperature waveform for brazing process. 
a)
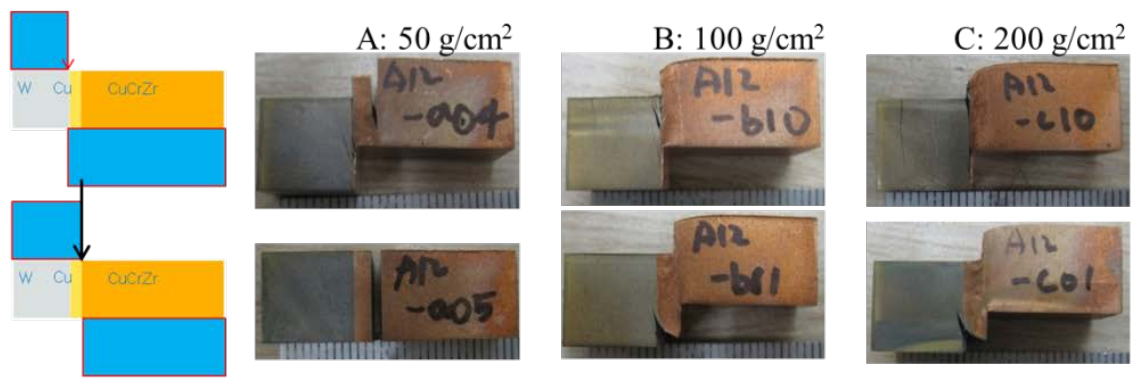

b)

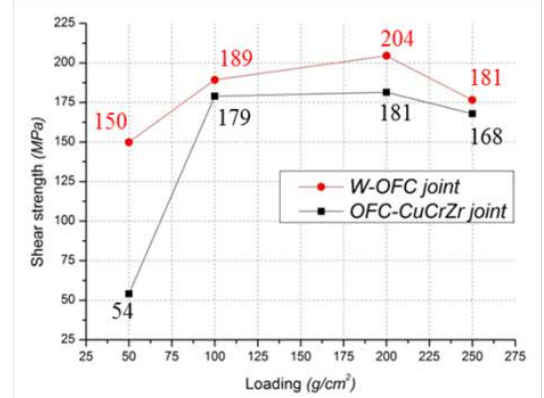

Fig. 2. Shear strength test of tungsten brazed sample. a) test points and pictures of samples after the test, b) Measured shear strength as a function of pressure load $\left(\mathrm{g} / \mathrm{cm}^{2}\right)$ during the brazing process (red: W-OFHC joint, black: OFHC-CuCrZr joint). 
a)

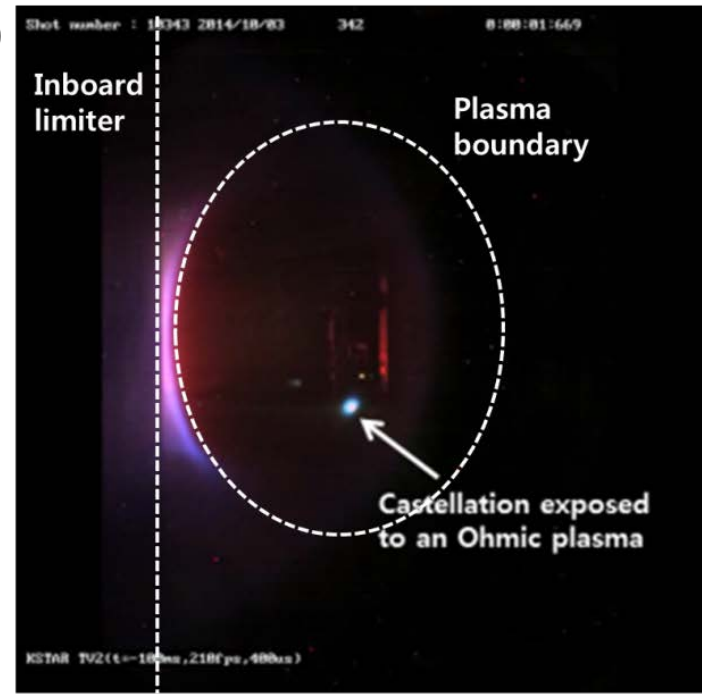

b)

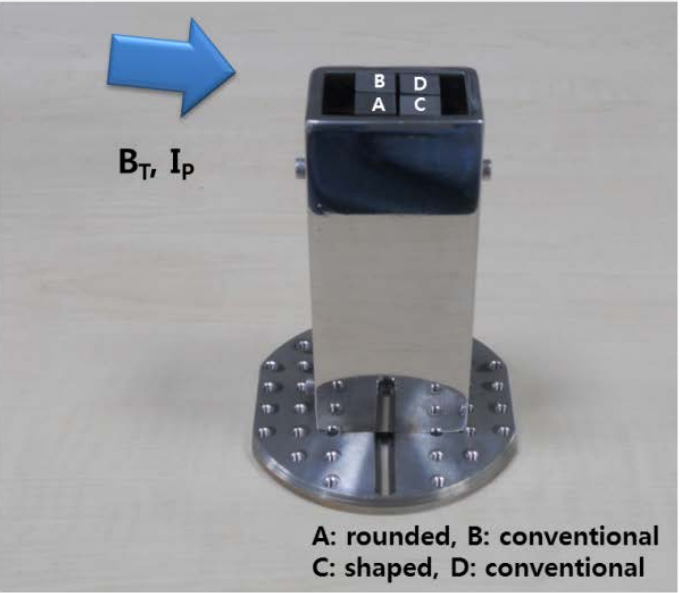

C)

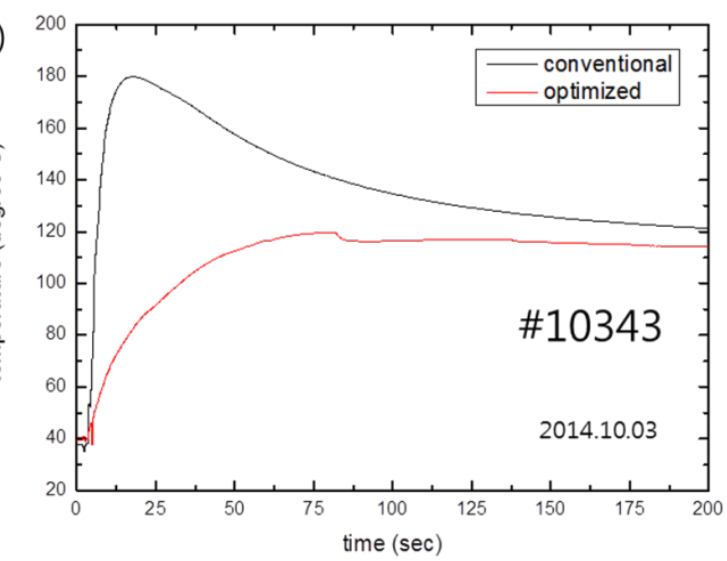

Fig. 3. Castellation samples exposed to an Ohmic discharge in KSTAR. a) Visible CCD image of the exposure, b) exposed castellation with unshaped and shaped blocks, c) the temperature evolution of each block measured by thermocouples. 
a)

Heat flux $\left(5^{\circ}\right)$
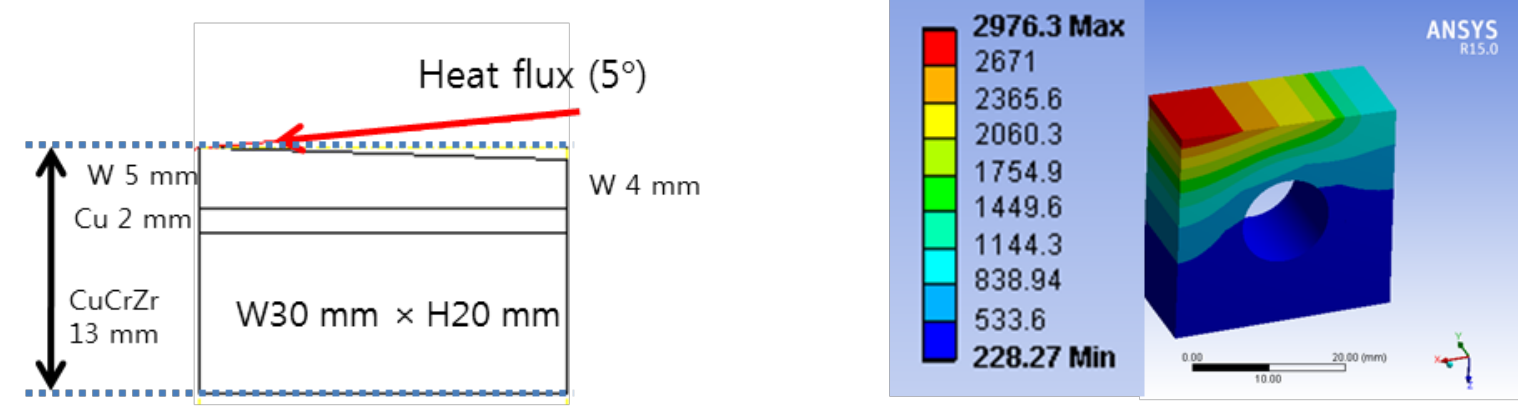

b)
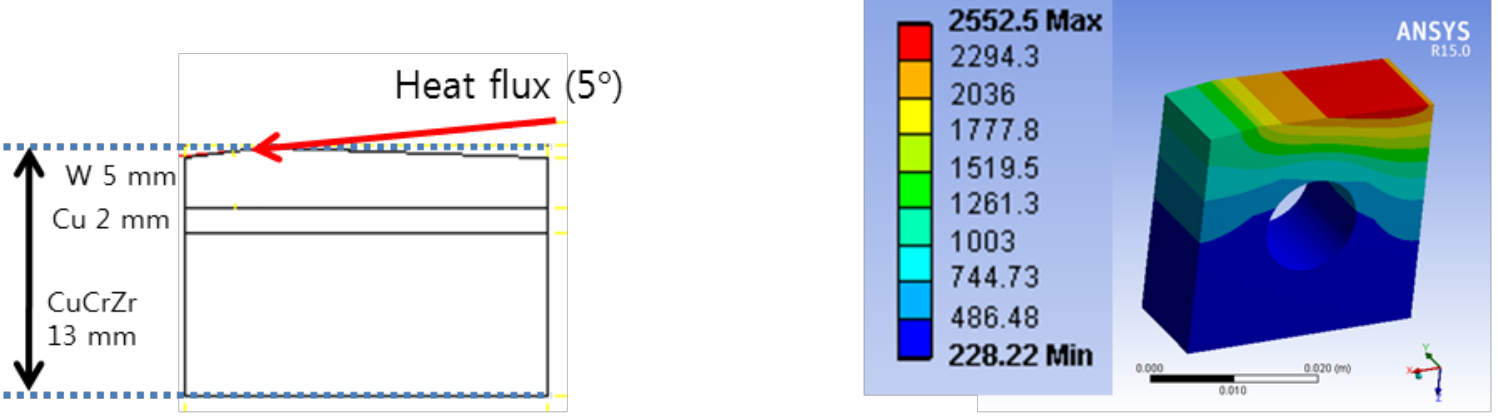

c)

Heat flux $\left(5^{\circ}\right)$
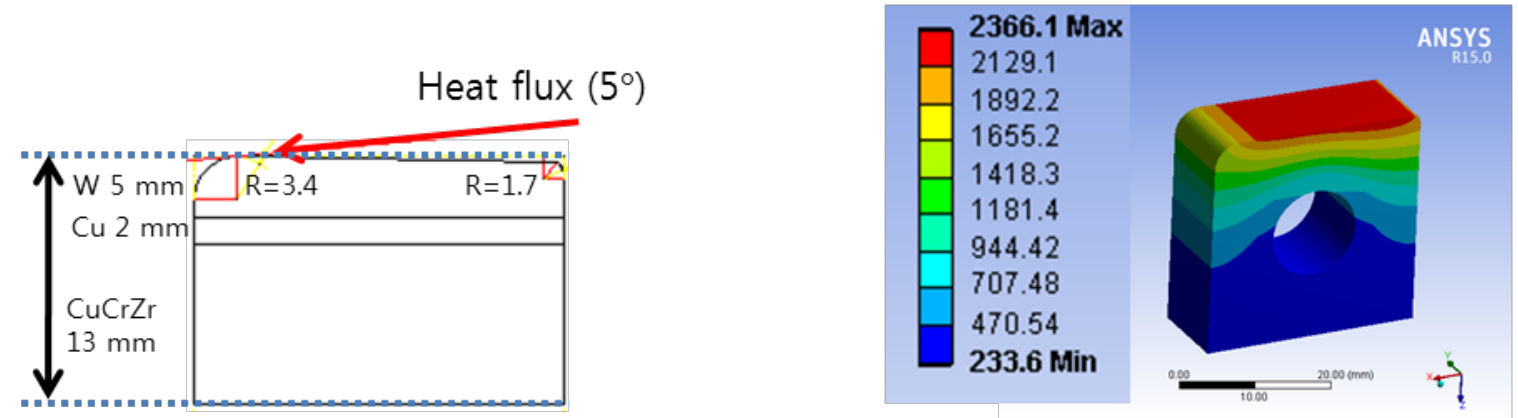

Fig. 4. Three different shapes of castellation structures for further optimization of the shape together with ANSYS simulation results. a) base design, b) double chamfered design, c) rounded design 
a)

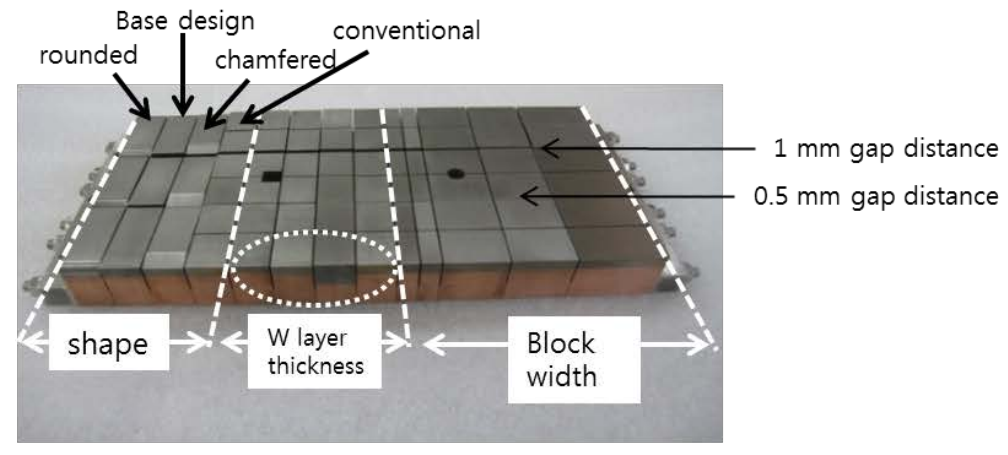

b)

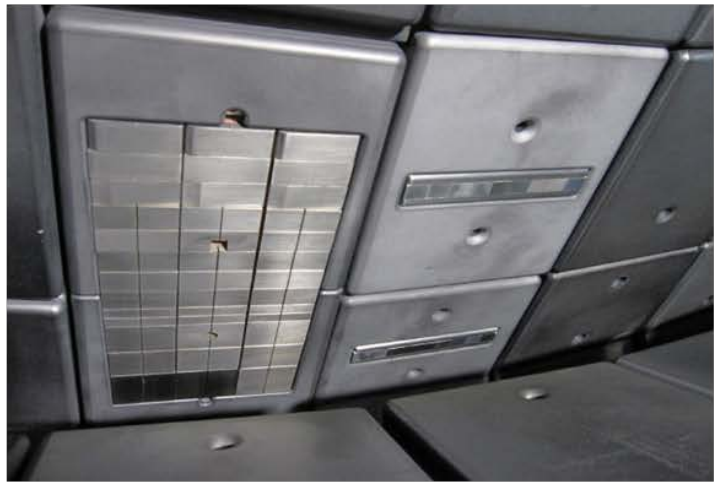

KSTAR Div. IRTV \#11325 ( $\left.\mathrm{t}_{\mathrm{m}}=8.1134 \mathrm{sec}, \mathrm{t}_{\mathrm{ep}}=1.5 \mathrm{~ms}\right)$

c)

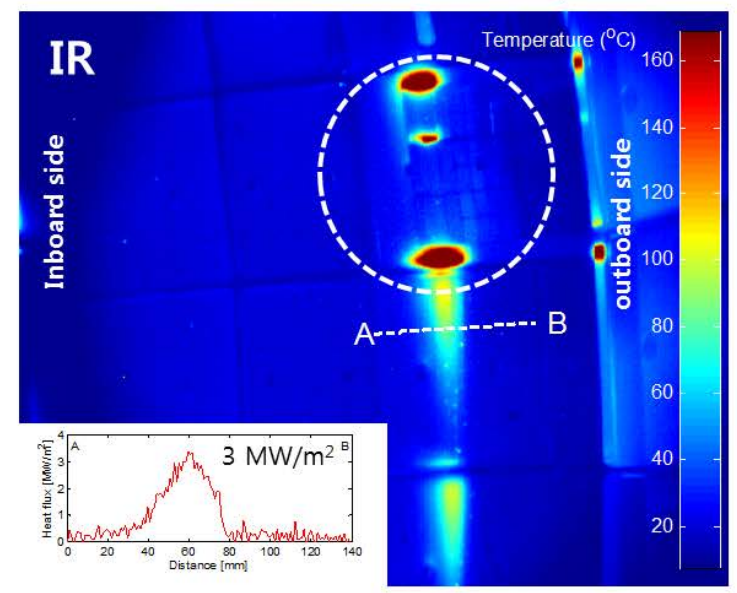

Fig. 5. a) Manufactured castellation blocks with different design parameters such as tungsten thickness, block width, and gap distance, b) block installed in KSTAR, c) IR observation during an H-mode plasma shot from the top. 


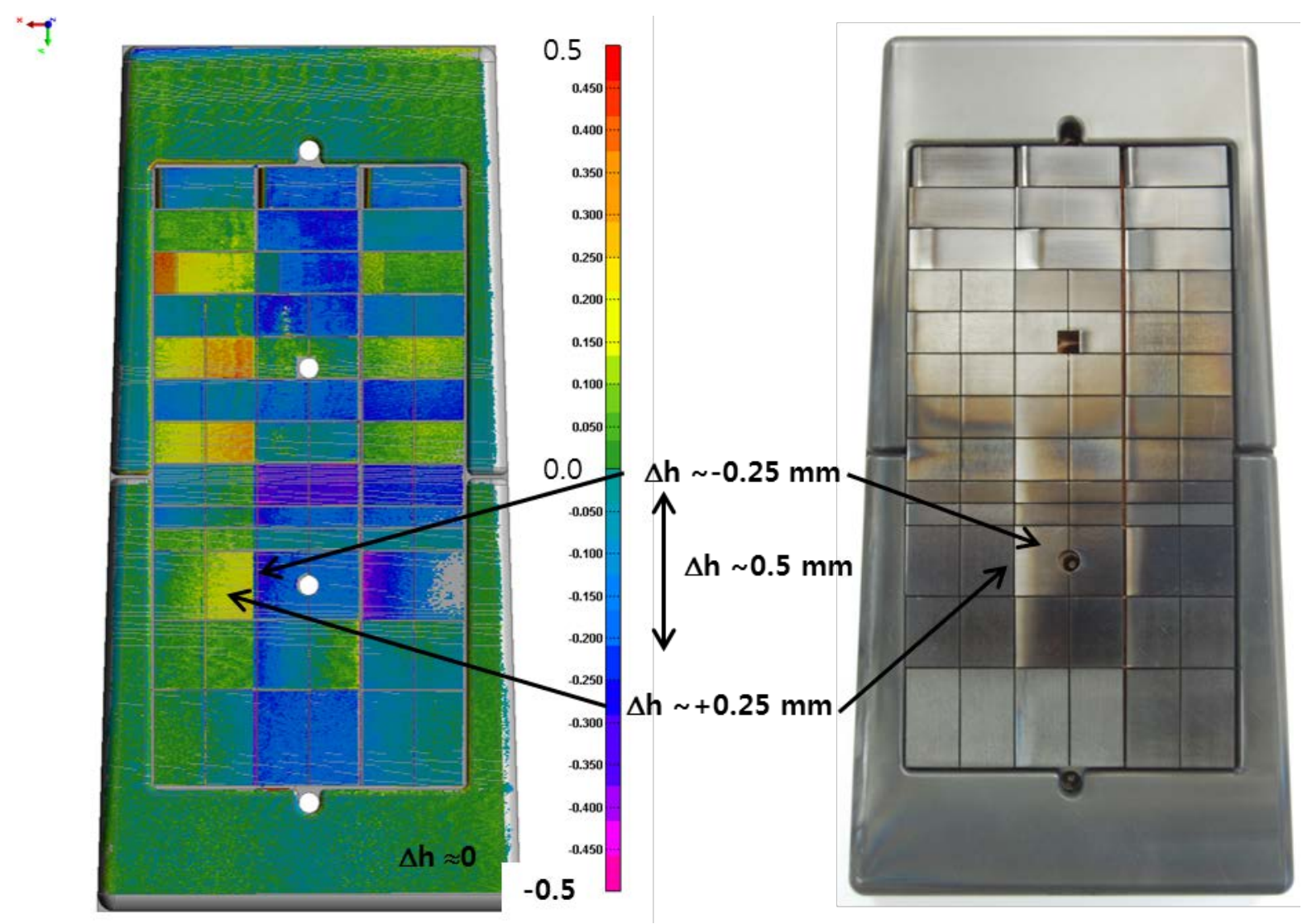

Fig. 6. The color map of the level of misalignment and a picture of tungsten block tile after the campaign. 